(A) Check for updates

Cite this: Food Funct., 2021, 12, 2631

\title{
The influence of Castanea sativa Mill. flower extract on hormonally and chemically induced prostate cancer in a rat model
}

\author{
E. Nascimento-Gonçalves, ${ }^{a, b}$ F. Seixas, $\hat{\dagger}^{\mathrm{c}}$ M. Silva, $\hat{\dagger}^{\mathrm{d}}$ M. Fardilha, ${ }^{\mathrm{e}}$ R. Ferreira, ${ }^{\mathrm{b}}$ \\ M. J. Neuparth, ${ }^{f}$ A. I. Faustino-Rocha, ${ }^{a, 9}$ B. Colaço, ${ }^{a}$ C. Venâncio, ${ }^{a}$ L. Barros, \\ I. C. F. R. Ferreira, (D ${ }^{h}$ M. M. Oliveira, (D) d F. Peixoto, ${ }^{d}$ E. Rosa ${ }^{a}$ and P. A. Oliveira (D) *a
}

\begin{abstract}
Prostate cancer (PCa) is one of the most common cancers in men, with a huge impact on their health. The use of Castanea sativa Mill. flowers (CFs) in beverages has been reported, through ancestral claims, as having health benefits. In vitro research has evidenced the properties of CFs, such as antitumor and antioxidant activities. This study aimed to evaluate the effects of CF extract in an animal model of PCa. Forty male Wistar Unilever rats were randomly assigned to four groups: control, induced, control $+\mathrm{CF}$, and induced + CF groups. Animals from the induced groups were exposed to a multistep protocol for PCa induction. The CF extract, rich in trigalloyl-HHDP-glucoside and obtained via decoction, was administered to the CF groups in drinking water (3 mg per animal per day) for 49 weeks. Animals were sacrificed at 61 weeks of age. Regarding the effects of CFs on dorsolateral prostate tumorigenesis, no significant differences were observed between the induced and induced + CF groups. However, animals exposed to the CF extract showed fewer inflammation areas on the dorsolateral prostate lobe than those not exposed to CF. Moreover, the CF extract alleviated the hepatic oxidative stress associated with the multistep protocol, resulting in lower levels of lipid peroxidation. These results suggest that CF extract has antioxidant and anti-inflammatory properties.
\end{abstract}

Received 4th January 2021, Accepted 5th February 2021

DOI: $10.1039 /$ d1fo00029b

rsc.li/food-function cancer prevention and progression (conversion of tumor cells to a malignant phenotype and to invasive disease). ${ }^{4}$ Natural compounds have been widely used to prevent and even treat several diseases, including cancer., ${ }^{5,6}$ Over $60 \%$ of anti-cancer drugs are obtained from natural products, including plants, marine organisms and microbes. ${ }^{5}$ The active ingredients from natural products, such as alkaloids, flavonoids, terpenoids, polysaccharides and saponin, have different anti-cancer activities. These compounds may inhibit cell proliferation, induce apoptosis, and reduce the activity of metalloproteinases and cell invasion. ${ }^{7}$ Additionally, natural compounds also exhibit anti-inflammatory, analgesic, immunomodulatory and antiviral properties. ${ }^{5}$ Until now, several natural compounds were experimentally evaluated in in vivo PCa models. For example, the incidence of invasive carcinomas in Lobund-Wistar rats induced by $N$-methyl- $N$-nitrosourea (MNU) and treated with genistein, an isoflavone of soy, was lower when compared with non-treated animals. ${ }^{8}$ Acticoa powder, a cocoa polyphenolic extract, reduced the incidence of PCa in Wistar-Unilever rats exposed to $\mathrm{MNU}$, followed by chronic androgen stimulation with testosterone. ${ }^{9}$ Crataeva nurvala, a typical Indian medicinal plant, showed anticancer activity against MNU-induced PCa in Wistar rats. ${ }^{10}$ These results support the use of this PCa model 
to evaluate chemopreventive and therapeutic properties of natural compounds.

Chestnuts are trees with a high impact on the Portuguese economy, mainly in the north-east of the country, due to nut (Castanea sativa Miller) production. ${ }^{11}$ The nuts are traditionally used for human and animal feed, by incorporation in many dishes and desserts of Portuguese gastronomy. Moreover, chestnuts seem to have beneficial properties for human health. ${ }^{12-14}$ The leaves may be used for medicinal purposes, such as colds, diarrhoea and to control blood cholesterol levels. ${ }^{15,16}$ Their flowers are reported by ancestral claims as having health benefits as mucolytic, antispasmodic and anti-dysenteric agents. ${ }^{17}$ The phytochemical profile of chestnut tree flowers includes: flavonoids, such as catechin, myricetin 3-O-glucoside, quercetin 3-O-rutinoside, quercetin 3-O-glucoside, kaempferol 3-O-rutinoside and kaempferol 3-O-glucoside and phenolic compounds, such as trigalloyl-HHDP-glucoside and pentagalloyl glucoside. ${ }^{15}$ The in vitro antitumor activity of decoctions and infusions of CF was evaluated by Carocho and colleagues in four human tumour cell lines: MCF7 (breast adenocarcinoma), HCT15 (colon carcinoma), HeLa (cervical carcinoma) and HepG2 (hepatocellular carcinoma); higher antitumoral activity against the colon and hepatocellular cancer cell lines was observed. ${ }^{18}$ These authors concluded that the anticancer properties may be related to the presence of two polyphenols: trigalloyl-HHDP-glucoside and pentagalloyl-glucoside, found in the chestnut flowers. ${ }^{18}$

The present study aimed to evaluate the effect of CF in vivo, using an animal model of chemically and hormonally induced PCa. Furthermore, we also assessed the hepatic toxicity and antioxidant response to the administration of the $\mathrm{CF}$ extract.

\section{Materials and methods}

\subsection{Chestnut flower samples and decoction preparation}

Castanea sativa Mill. Flowers (CFs), corresponding to upright catkins during anthesis (flower fully opened and functional), were collected in June 2017 in Bragança, (north-eastern Portugal). The specimens were lyophilized (FreeZone 4.5, Labconco, Kansas, USA), milled down to a fine powder, and stored at room temperature, without humidity until the analysis. For the decoctions' preparation, the lyophilized flowers $(1 \mathrm{~g})$ were added to $200 \mathrm{~mL}$ of boiling distilled water, boiled for $5 \mathrm{~min}$, and then left to stand at room temperature for 5 minutes. After filtration through a Whatman filter paper, the obtained decoctions were frozen and lyophilized. Based on the phenolic compounds' concentration and on the mean value of the $\mathrm{GI}_{50}$ values obtained in the in vitro studies $\left(300 \mu \mathrm{g} \mathrm{mL} \mathrm{m}^{-1}\right)$ performed previously by Carocho et al. ${ }^{18}$ the extract was administrated at the quantity of $3 \mathrm{mg}$ per day per animal in the total drinking water amount per day. This amount $(10 \times$ the concentration of the $\mathrm{GI}_{50}$ value) was chosen to guarantee the activity in vivo and to assure the phenolic compounds concentration in the drinking water.

\subsection{Phenolic compound profiles and stability of the aqueous extracts}

The phenolic compounds were determined in a Dionex Ultimate 3000 UPLC (Thermo Scientific, San Jose, CA, USA) connected to a diode-array detector (DAD, 280, 330 and $370 \mathrm{~nm}$ ) and a mass spectrometer equipped with an ESI source (Linear Ion Trap LTQ XL, Thermo Finnigan, San Jose, CA, USA), following a procedure previously reported. ${ }^{19}$ The identification was performed considering data reported in the literature and the phenolic compounds previously identified in chestnut flowers. ${ }^{11}$ For quantitative analysis, a calibration curve for each available phenolic standard was constructed based on the UV signal or, when no commercial standard was available, a similar compound from the same phenolic group was used as a standard and the results were expressed in $\mu \mathrm{g}$ per $\mathrm{mL}$ of decoction. The stability of the drinking water was evaluated during 5 consecutive days, at room temperature. In this study, the aqueous extract was prepared at the feeding concentration and analyzed daily through an LC-DAD-ESI/MS system, to detect the degradation of any compounds.

\subsection{Animals}

Forty male Wistar Unilever rats (Rattus norvegicus) 4 weeks of age were obtained from Charles River Laboratories (France). The animals were maintained under controlled conditions of temperature $\left(23 \pm 2{ }^{\circ} \mathrm{C}\right)$, humidity (50 $\left.\pm 10 \%\right)$, air system filtration (10-20 ventilations per hour) and light: dark cycles (12 h:12 h). They had ad libitum access to water and a standard laboratory diet (Mucedola 4RF21®, Milan, Italy). Cages were cleaned and changed weekly, and the water was renewed every three consecutive days. Animals were weighed weekly and the ponderal homogeneity index $\left[\mathrm{PH}=2 W_{\mathrm{i}} /\left(W_{\mathrm{i}}+W_{\mathrm{h}}\right)\right]$ and ponderal gain $\left[\mathrm{PG}=W_{2}-W_{1} / W_{2} \times 100\right]$ were determined, with $W_{\mathrm{i}}$ being the lowest animal weight, $W_{\mathrm{h}}$ the highest animal weight, $W_{1}$ the initial body weight and $W_{2}$ the final body weight. All procedures were performed according to the European Directive 2010/63/EU on the protection of animals used for scientific purposes and approved by the Portuguese authorities (Direcção Geral Alimentação e Veterinária, Approval no. 021326).

\subsection{Experimental procedures}

After one week of acclimatization, animals were randomly assigned to four experimental groups as follows (Fig. 1): the control group $(n=10)$, induced group $(n=15)$, control $+\mathrm{CF}$ group $(n=5)$ and induced + CF group $(n=10)$. At 12 weeks of age, the animals from the induced and induced $+\mathrm{CF}$ groups received a subcutaneous injection of the anti-androgenic drug flutamide (50 $\mathrm{mg} \mathrm{kg}^{-1}$; TCI Chemicals, Portland, OR, USA) for 21 consecutive days. Twenty-four hours after the last flutamide administration, testosterone propionate (TCI Chemicals, Portland, OR, USA) was dissolved in corn oil and subcutaneously administered to the animals at a dose of $100 \mathrm{mg}$ $\mathrm{kg}^{-1}$. Forty-eight hours later, they were intraperitoneally injected with the carcinogen agent MNU (Isopac ${ }^{\circledR}$, Sigma 


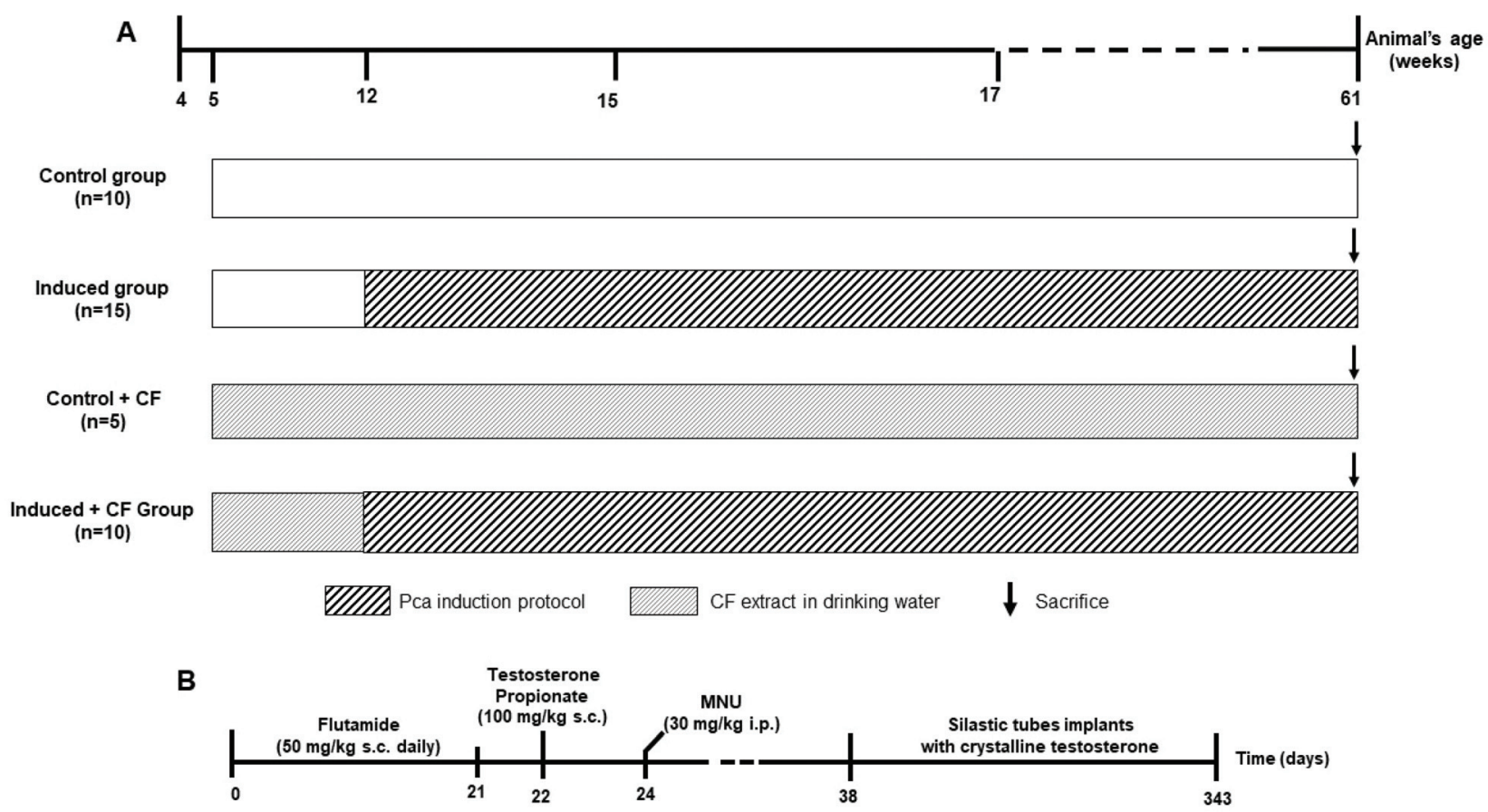

Fig. 1 (A) The experimental protocol and (B) the PCa induction protocol.

Chemical Co., Madrid, Spain) at a dose of $30 \mathrm{mg} \mathrm{kg}^{-1}$. Two weeks later, silastic tubes filled with crystalline testosterone (Sigma Chemical Co., Madrid, Spain) were subcutaneously implanted in the interscapular region of animals previously anesthetized with ketamine (75 $\mathrm{mg} \mathrm{kg}^{-1}$, Imalgene ${ }^{\circledR}$ 1000, Merial S.A.S., Lyon, France) and xylazine (10 $\mathrm{mg} \mathrm{kg} \mathrm{kg}^{-1}$, Rompun ${ }^{\circledR} 2 \%$, Bayer Healthcare S.A., Kiel, Germany), remaining until the end of the experimental protocol. Animals from the control $+\mathrm{CF}$ and induced $+\mathrm{CF}$ groups were exposed to the $\mathrm{CF}$ extract in drinking water, at a dose of $3 \mathrm{mg}$ per animal per day, since the beginning of the carcinogenic protocol and for 49 weeks. The animals' food and water consumption was recorded weekly at the same time and body weight was registered once a month. Animals were sacrificed at 61 weeks of life through an intraperitoneal injection of ketamine $\left(75 \mathrm{mg} \mathrm{kg}^{-1}\right.$, Imalgene ${ }^{\circledR}$ 1000, Merial S.A.S., Lyon, France) and xylazine (10 $\mathrm{mg} \mathrm{kg} \mathrm{kg}^{-1}$, Rompun ${ }^{\circledR}$ 2\%, Bayer Healthcare S.A., Kiel, Germany), followed by exsanguination by cardiac puncture. A complete necropsy was performed in all animals. All organs were collected and weighed. The anterior prostate lobes and seminal vesicle were individualized and weighed separately. The ventral and dorsolateral prostate surrounding the prostatic urethra were weighed as a block.

\subsection{Serum biochemistry}

The blood samples were allowed to clot and were centrifuged at $3000 \mathrm{rpm}$ for 15 minutes $\left(4^{\circ} \mathrm{C}\right)$. The serum was separated and frozen at $-80{ }^{\circ} \mathrm{C}$ until use. Serum concentrations of albumin, total protein, glucose and alanine aminotransferase
(ALT) were determined in an autoanalyzer (Prestige 24i, Cormay PZ).

\subsection{Histological analysis}

The prostate, liver and kidneys were fixed in $10 \%$ neutral buffered formalin and processed for histological analysis according to the routine technique. The following trimming procedure was performed in all experimental groups: anterior prostate, ventral prostate and seminal vesicle were bisected midway and both sections were embedded in paraffin. The dorsolateral prostate was transversely sectioned into three slices and embedded in paraffin with the cut surface down. The tissue sections were stained with hematoxylin and eosin for histological analysis. The severity of non-proliferative and inflammatory lesions was scored semi-quantitively in three grades, as follows: (1) minimal - occurring in less than $10 \%$ of prostate tissue; (2) mild - 10-50\%; and (3) severe - more than $50 \%$. All preneoplastic and neoplastic lesions were classified according to Bosland et al. ${ }^{20}$

\subsection{Oxidative stress parameters}

2.7.1. Sample preparation. Liver samples were collected from animals of different experimental groups for oxidative stress analysis. A liver portion was weighed $( \pm 1 \mathrm{~g})$ and added to $20 \%(\mathrm{w} / \mathrm{v})$ ice-cold phosphate buffer. The samples were mechanically homogenized and sonicated for 2 minutes. The resulting homogenate was centrifuged in three different centrifugations cycles, at $4{ }^{\circ} \mathrm{C}: 1500 \mathrm{~g}, 10$ minutes (PS1-total membrane fraction); $8000 \mathrm{~g}, 10$ minutes (mitochondrial fraction); 
and $14000 g$, 10 minutes (PS2-mitochondrial fraction). The supernatant resulting from the last centrifugation was immediately used for the assessment of the reduced glutathione (GSH) and oxidised glutathione (GSSG) ratio, and to evaluate the antioxidant enzymes' activity. Lipid peroxidation was evaluated in both the total and mitochondrial membrane fractions. The biuret method was used to determine the total protein content from all pellets and supernatant collected.

2.7.2. Lipid peroxidation. Lipid peroxidation was evaluated spectrophotometrically, at $532 \mathrm{~nm}$, using the appearance of malondialdehyde (MDA), according to Ottolenghi (1958) with minor modifications. ${ }^{21}$ This method allows the determination of the lipidic hydroperoxides from the amount of thiobarbituric acid reactive substances (TBARS) formed. A volume corresponding to $0.5 \mathrm{mg}$ of protein was collected from the total and mitochondrial lipidic fractions and added to $1 \mathrm{~mL}$ of the thiobarbituric acid reagent. The mixture was homogenized, heated for 15 minutes at $100{ }^{\circ} \mathrm{C}$, and cooled down by ice immersion. A centrifugation cycle was performed at $1600 \mathrm{~g}$ for 10 minutes, at $4{ }^{\circ} \mathrm{C}$, in order to collect the supernatant for the assay. Results were expressed as $\mu \mathrm{M}$ (MDA), using the molar coefficient extinction of $1.56 \times 10^{5} \mathrm{M}^{-1} \mathrm{~cm}^{-1}$.

2.7.3. GSH/GSSG. The GSH and GSSG ratio was determined by evaluating the GSH and GSSG levels. GSH and GSSG concentrations were assessed fluorometrically, at $339 \mathrm{~nm}$ (excitation) and $426 \mathrm{~nm}$ (emission) using the fluorochrome orthophthalaldehyde (OPT), as described by Hissin and Hilf (1976). ${ }^{22}$ To determine the GSH levels, the supernatant collected from all samples was incubated in a solution containing potassium phosphate buffer (100 mM, EDTA $5 \mathrm{mM}, \mathrm{pH} 8.0$ ) and OPT ( $1 \mathrm{mg} \mathrm{mL}^{-1}$ ethanol), for 15 minutes at room temperature. The samples' supernatant was incubated for 30 minutes, at room temperature, with $\mathrm{N}$-ethylmaleimide to assess the GSSG concentration. A volume of $\mathrm{NaOH}(100 \mathrm{mM})$ and OPT ( $1 \mathrm{mg} \mathrm{mL} \mathrm{mL}^{-1}$ ethanol) was added to the mixture and incubated in the darkness for 15 minutes. Concentrations of GSH and GSSG were obtained using standard curves made with known concentrations of GSH and GSSG, respectively. Results were expressed as the ratio of GSH/GSSG.

2.7.4. Antioxidant enzymes. All antioxidant enzyme assays were performed spectrophotometrically at $30^{\circ} \mathrm{C}$, except for catalase (CAT) assessment. CAT activity was evaluated according to Del Río (1977), ${ }^{23}$ using a Clark-type oxygen electrode. The addition of a sample volume corresponding to $0.5 \mathrm{mg}$ protein to a mix containing potassium phosphate buffer $(50 \mathrm{mM}, \mathrm{pH}$ $7.0)$ and hydrogen peroxide $(8.82 \mathrm{M})$, started the enzymatic reaction. CAT activity was expressed in mmol $\mathrm{H}_{2} \mathrm{O}_{2}$ consumed per min Per $\mathrm{mg}$ protein. Superoxide dismutase (SOD) was assayed at $560 \mathrm{~nm}$, as described by Payá (1992), ${ }^{24}$ using the xanthine-xanthine oxidase systems. The reaction mixture contained potassium phosphate buffer $(50 \mathrm{mM})$, EDTA $(1 \mathrm{Mm})$ at pH 7.4, hypoxanthine (10 mM), nitroblue tetrazolium chloride (NBT, $10 \mathrm{mM}$ ) and a volume of the sample corresponding to $0.5 \mathrm{mg}$ of protein. The kinetic reaction was started by adding xanthine oxidase $\left(0.0023 \mathrm{U} \mathrm{mol}^{-1}\right)$. Results were expressed as $\mathrm{U} \min ^{-1} \mathrm{mg}^{-1}$ protein. One unit of SOD corresponds to the amount of enzyme, inhibiting the reduction rate of NBT to formazan by $50 \%$. Glutathione reductase (GR) was assayed at $340 \mathrm{~nm}$, as described by Carlberg and Mannervik. ${ }^{25}$ The reaction system consisted of potassium phosphate buffer (100 mM, EDTA 0.5 mM, pH 7.4), NADPH (10 mM) and $1.5 \mathrm{mg}$ of enzymatic extract. GSSG $(100 \mathrm{mM})$ was added to the mixture to start the kinetic reaction. Results were expressed as $\mu \mathrm{mol}$ $\mathrm{NADPH}$ oxidized per min per mg protein. Glutathione- $S$-transferase (GST) was performed by the method described by Hatton at $340 \mathrm{~nm}$. The kinetic reaction was started by adding GSH $(100 \mathrm{mM})$ to the system reaction containing potassium phosphate buffer (100 mM, pH 7.0) and 2,4-dinitrochlorobenzene (CDNB, $100 \mathrm{mM}$ ). GST activity was expressed as $\mathrm{mM}$ of CDNB conjugated per min per mg protein.

\subsection{Statistical analysis}

The data of oxidative stress was statistically analysed by using ANOVA followed by Tukey's Multiple Comparison Test (GraphPad Prism software, version 7.0). The remaining continuous data were analysed with the Statistical Package for Social Sciences (SPSS) version 25 (Chicago, IL, USA), by using ANOVA followed by a Bonferroni test. Histological results were analysed using a Chi-square test. The organs' mean relative weight was determined (weight of the organ/final body weight of each animal). Data are presented as mean \pm standard error (S.E.) or mean \pm standard deviation (S.D.). Data was considered statistically significant for $p$ values lower than 0.05 .

\section{Results}

\subsection{Phenolic composition}

The phenolic profile of the CF decoctions extract is presented in Table 1. Twenty-seven compounds were detected, from which 14 were flavonoids and 13 were ellagitannins. These compounds were previously described by Carocho and colleagues in two types of aqueous extracts (infusions and decoctions), where trigalloyl-HHDP-glucoside, followed by pentagalloyl glucoside, were the most abundant compounds, as found in the decoction extract of this study. ${ }^{15}$ Moreover, quercetin 3$O$-glucuronide was the most abundant flavonoid. ${ }^{15}$ The stability of these extracts was studied during five consecutive days and the concentration of phenolic compounds did not decrease at day five (data not shown). Therefore, the drinking water was maintained up to a maximum of three days, to avoid compound degradation.

\subsection{Body weight and mortality rate}

The ponderal homogeneity index $(\mathrm{PH})$, mortality rate, mean initial and final animals' body weight, and ponderal gain (PG) may be observed in Table 2. The $\mathrm{pH}$ is an indicator of the initial homogeneity of the experimental groups. Animals from the control $+\mathrm{CF}$ group showed the highest $\mathrm{PH}$ variation (0.96) and the control group showed the lowest variation (0.85). Although the animals were acquired at the same age, their body weight was different. During the experimental work, two 
Table 1 The identification and quantification $\left(\mu \mathrm{g} \mathrm{mL} \mathrm{L}^{-1}\right.$ ) of the phenolic compounds present in the Castanea sativa flower decoction extract via LC-DAD-ESI/MS (mean \pm standard deviation)

\begin{tabular}{|c|c|c|c|c|c|c|}
\hline Peak & $\begin{array}{l}\mathrm{Rt} \\
(\mathrm{min})\end{array}$ & $\begin{array}{l}\lambda_{\max } \\
(\mathrm{nm})\end{array}$ & $\begin{array}{l}\text { Pseudomolecular } \\
\text { ion }[\mathrm{M}-\mathrm{H}]^{-}(\mathrm{m} / \mathrm{z})\end{array}$ & $\mathrm{MS}^{2}(\mathrm{~m} / \mathrm{z})(\%$ of base peak) & Tentative identification $^{a}$ & $\begin{array}{l}\text { Quantification } \\
\left(\mu \mathrm{g} \mathrm{mL}^{-1}\right)\end{array}$ \\
\hline 1 & 4.96 & 276 & 783 & 481(100), 301(37) & Pedunculagin isomer (bis-HHDP-glucose) & $51.1 \pm 0.3$ \\
\hline 4 & 7.67 & 274 & 937 & 637(100), 467(3), 301(3) & Trigalloyl-HHDP-glucose & $28.4 \pm 0.8$ \\
\hline 5 & 8.02 & 278 & 289 & 245(100), 203(66), 137(34) & $(+)$-Catechin & $11.7 \pm 0.3$ \\
\hline 6 & 13.77 & 276 & 939 & $631(23), 469(69), 169(100)$ & Pentagalloyl glucose & $54.4 \pm 0.7$ \\
\hline 9 & 15.46 & 278 & 907 & $767(55), 607(100), 467(55), 169(8)$ & Galloyl-HHDP derivative & $3.7 \pm 0.2$ \\
\hline 10 & 16.13 & 274 & 937 & $767(22), 637(36), 467(100), 301(15)$ & Trigalloyl-HHDP-glucoside & $259 \pm 1$ \\
\hline 11 & 16.65 & 358 & 493 & $317(100)$ & Myricetin $O$-glucuronide & $11.0 \pm 0.2$ \\
\hline 12 & 17.07 & 350 & 479 & $317(100)$ & Myricetin 3-O-glucoside & $6.4 \pm 0.1$ \\
\hline 13 & 17.30 & 274 & 937 & 767(5), 637(22), 467(100), 301(5) & Trigalloyl-HHDP-glucoside & $12.91 \pm 0.05$ \\
\hline 14 & 19.89 & 356 & 609 & $301(100)$ & Quercetin 3-O-rutinoside & $15.3 \pm 0.1$ \\
\hline 15 & 20.64 & 356 & 477 & $301(100)$ & Quercetin 3-O-glucuronide & $34 \pm 1$ \\
\hline 20 & 24.46 & 268 & 907 & 767(7), 607(33), 467(100), 169(8) & Galloyl-HHDP derivative & $40.5 \pm 0.9$ \\
\hline 21 & 25.11 & 348 & 447 & $285(100)$ & Kaempferol 3-O-glucoside & $5.14 \pm 0.04$ \\
\hline 22 & 26.00 & 354 & 477 & $315(100)$ & Isorhamnetin $O$-hexoside & $3.2 \pm 0.4$ \\
\hline 23 & 26.25 & 354 & 491 & $315(100)$ & Isorhamnetin $O$-glucuronide & $3.4 \pm 0.3$ \\
\hline 24 & 27.71 & 274 & 907 & $767(7), 607(47), 467(100), 169(11)$ & Galloyl-HHDP derivative & $19.7 \pm 0.6$ \\
\hline 25 & 29.87 & $250 / 368$ & 343 & 328(93), 313(100), 298(43) & Tri-O-methylellagic acid & $1.0 \pm 0.1$ \\
\hline 26 & 32.38 & 358 & 609 & $463(55), 301(100)$ & Quercetin $O$-rhamnosyl hexoside & $2.20 \pm 0.01$ \\
\hline \multirow[t]{4}{*}{27} & 33.13 & 356 & 519 & $477(44), 315(100)$ & Isorhamnetin $O$-acetylhexoside & $1.08 \pm 0.01$ \\
\hline & & & & & Total flavonoids & $139.0 \pm 0.5$ \\
\hline & & & & & Total ellagitannins & $524.2 \pm 0.4$ \\
\hline & & & & & Total phenolic compounds & $663.1 \pm 0.9$ \\
\hline
\end{tabular}

Calibration curves: catechin $\left(y=132.76 x-59.658 ; R^{2}=1\right)$; gallic acid $\left(y=556.94 x-738.37 ; R^{2}=0.999\right)$; isorhamnetin-3-O-glucoside $(y=262.31 x$ - 9.8958; $\left.R^{2}=1\right)$; kaempferol-3-O-glucoside $\left(y=190.75 x-36.158 ; R^{2}=1\right)$; kaempferol-3-O-rutinoside $\left(y=175.02 x-43.877 ; R^{2}=0.999\right)$; myricetin $\left(y=778 x-1454.3 ; R^{2}=0.999\right) ;$ quercetin-3-O-glucoside $\left(y=316.48 x-2.9142 ; R^{2}=1.000\right)$; and quercetin-3-O-rutinoside $\left(y=222.79 x-243.11 ; R^{2}\right.$ $=0.999) \cdot{ }^{a}$ Carocho et al. $(2014) \cdot{ }^{15}$

Table 2 Number of animals, ponderal homogeneity index (PH), mortality rate, initial and final animal body weights (g) [mean \pm standard error (SE)], and ponderal gain (PG) for all experimental groups

\begin{tabular}{|c|c|c|c|c|c|c|c|}
\hline & $\begin{array}{l}\text { Initial number } \\
\text { of animals }\end{array}$ & $\begin{array}{l}\text { Final number } \\
\text { of animals }\end{array}$ & $\mathrm{PH}$ & $\begin{array}{l}\text { Mortality rate } \\
(\%)\end{array}$ & $\begin{array}{l}\text { Initial weight } \\
(\mathrm{g})\end{array}$ & $\begin{array}{l}\text { Final weight } \\
(\mathrm{g})\end{array}$ & PG \\
\hline Control & 10 & 10 & 0.85 & 0 & $144 \pm 4.2$ & $546 \pm 3.5^{a}$ & $73.5 \pm 0.5^{a}$ \\
\hline Control + CF & 5 & 5 & 0.96 & 0 & $157 \pm 4.4$ & $561 \pm 8.3$ & $72.0 \pm 0.6^{b}$ \\
\hline Induced $+\mathrm{CF}$ & 10 & 9 & 0.94 & 10 & $172 \pm 1.3$ & $534 \pm 7.1$ & $67.8 \pm 0.5$ \\
\hline
\end{tabular}

${ }^{a} p<0.05$ versus the induced group. ${ }^{b} p<0.05$ versus the induced $+\mathrm{CF}$ group.

animals died: one animal from the induced group and one animal from the induced + CF group. Data from these animals was excluded from the study. At the beginning of the experimental work, the mean animals' body weight was not statistically different among the groups. However, a statistically significant difference was observed in the mean body weight between the control and induced groups at the end of the study $(p<0.05)$. The PG was higher in the control and control $+\mathrm{CF}$ groups, when compared with the induced and induced + CF groups, respectively $(p<0.05)$. Table 3 shows the mean values of food and water consumption at the beginning and at the end of experimental work. Concerning the food consumption, a significant difference $(p<0.05)$ was observed between the induced and induced + CF groups in week one of the study. The animals exposed to the CF extract showed the highest water consumption at the beginning and the lowest intake at the end of the study. Table 4 shows the relative organ weight. The induced $+\mathrm{CF}$ group showed the highest mean relative prostate weight $(0.0041 \pm 0.0001)$, which is statistically different from the control $+\mathrm{CF}$ group $(p<0.05)$. The liver mean relative weight was higher in animals exposed to the CF extract when compared with those not exposed. Statistically 
Table 3 Mean food and water consumption $(\mathrm{g})$ (mean $\pm \mathrm{SE}$ ) at the beginning and at the end of the experimental protocol

\begin{tabular}{|c|c|c|c|c|c|}
\hline & & Control $(n=10)$ & Induced $(n=14)$ & Control + CF $(n=5)$ & Induced $+\mathrm{CF}(n=9)$ \\
\hline \multirow[t]{2}{*}{ Food consumption $(\mathrm{g})$} & Initial & $14.9 \pm 0.1$ & $13.7 \pm 1.2^{a}$ & 18.9 & $17.2 \pm 0.1$ \\
\hline & Final & $19.6 \pm 0.6^{b}$ & $20.9 \pm 0.1$ & 20.2 & $20.9 \pm 0.1$ \\
\hline \multirow[t]{2}{*}{ Water consumption $(\mathrm{g})$} & Initial & $19.6 \pm 0.01^{b, c}$ & $18.41 \pm 0.1^{a}$ & $23.4^{b}$ & $21.9 \pm 0.2$ \\
\hline & Final & $24.1 \pm 0.1^{b, c}$ & $25.5 \pm 0.5^{a}$ & $11.6^{a}$ & $15.4 \pm 0.0$ \\
\hline
\end{tabular}

${ }^{a} p<0.05$ versus the induced $+\mathrm{CF}$ group. ${ }^{b} p<0.05$ versus the induced group. ${ }^{c} p<0.05$ versus the control $+\mathrm{CF}$ group.

Table 4 Mean relative organ weights $(\mathrm{g})$ in each experimental group (mean $\pm \mathrm{SE}$ )

\begin{tabular}{|c|c|c|c|c|}
\hline & Control $(n=10)$ & Induced $(n=14)$ & Control + CF $(n=5)$ & Induced $+\mathrm{CF}(n=9)$ \\
\hline Liver & $0.0224 \pm 0.0014^{b}$ & $0.0256 \pm 0.0006^{c}$ & $0.0273 \pm 0.0006^{c}$ & $0.0325 \pm 0.0009$ \\
\hline
\end{tabular}

significant differences were observed between the control groups (control and control $+\mathrm{CF}, p<0.05$ ) and between the induced groups (induced and induced $+\mathrm{CF}, p<0.05$ ).

\subsection{Blood sample analysis}

The animals' biochemical profile may be consulted in Table 5 . No significant differences were observed in the serum levels of albumin and ALT among the groups. Although the differences were not statistically significant, glucose serum levels were lower in animals exposed to the CF extract than in those not exposed, either in the control or induced groups.

\subsection{Histopathology}

The prostate lesions identified in each experimental group are listed in Tables 6 and 7 and some lesions may be observed in Fig. 2. Prostate lesions were classified as dysplasia, prostatic intraepithelial neoplasia (PIN), and microinvasive carcinoma.

Animals from the control group exposed to the CF extract presented an increased frequency in the dorsolateral prostate of preneoplastic, dysplastic and PIN lesions. In the induced groups, CF did not significantly change the frequency of dysplasia, PIN, and neoplastic lesions (microinvasive carcinoma). Regarding the ventral and anterior prostate lobes, histological lesions were only observed in animals from the induced $+\mathrm{CF}$ group; in these lobes CF exposure slightly increased the lesion frequency, although the differences were not statistically sig- nificant. When combining the data from all the prostate lobes, $\mathrm{CF}$ increased dysplasia in the controls and tended to increase PIN $(p=0.08)$, but did not significantly affect induction of dysplasia, PIN and microinvasive carcinoma in the induced groups (Table 7).

Data about inflammation on the dorsolateral prostate lobe, the most affected lobe in this protocol, may be observed in Table 8. Inflammation in the dorsolateral prostate lobe was observed in all experimental groups. The most extensive and severe inflammation foci were observed in the induced group, with $50.0 \%(7 / 14)$ of the rats exhibiting severe inflammation of prostate tissue, whereas all animals of the induced + CF group showed less extensive inflammation. Regarding the liver histology, only three animals (33.3\%) from the induced + CF group developed panlobular, but moderate, hydropic changes, while all the other animals showed occasional, small and slight hydropic change foci. Occasional fatty change foci were observed in rats from the induced group and in two obese animals from the control group. No severe degenerative, necrotic or inflammatory changes were observed in the assay. In some groups (induced and induced $+\mathrm{CF}$ ) we also observed occasional small foci of coagulative to liquefactive necrosis, or isolated necrotic cells. Mitosis, anisokaryosis or multinucleated hepatocytes were rarely observed.

Regarding the kidneys, no severe nor diffuse necrotic and/ or inflammatory foci were observed in all groups in the study

Table 5 Biochemical profiles of all the experimental groups (mean \pm SE)

\begin{tabular}{|c|c|c|c|c|}
\hline & Control $(n=10)$ & Induced $(n=14)$ & Control + CF $(n=5)$ & Induced $+\mathrm{CF}(n=9)$ \\
\hline $\operatorname{Albumin}\left(\mathrm{g} \mathrm{L}^{-1}\right)$ & $42.45 \pm 2.16$ & $40.56 \pm 1.07$ & $38.24 \pm 2.40$ & $37.18 \pm 1.66$ \\
\hline Total protein $\left(\mathrm{g} \mathrm{L}^{-1}\right)$ & $63.14 \pm 2.60^{a}$ & $57.01 \pm 0.86$ & $54.51 \pm 4.09$ & $50.51 \pm 3.79$ \\
\hline Glucose $\left(\mathrm{mg} \mathrm{dL}^{-1}\right)$ & $265.39 \pm 24.58$ & $254.16 \pm 13.01$ & $236.14 \pm 20.56$ & $225.92 \pm 25.37$ \\
\hline $\operatorname{ALT}\left(\mathrm{U} \mathrm{L}^{-1}\right)$ & $38.93 \pm 4.65$ & $39.15 \pm 2.91$ & $34.40 \pm 8.48$ & $24.48 \pm 2.02$ \\
\hline
\end{tabular}

${ }^{a} p<0.05$ versus the induced group. 
Table 6 Number of animals (\%) with histological lesions in prostate lobes in each experimental group (mean \pm S.E.)

\begin{tabular}{|c|c|c|c|c|}
\hline & $\begin{array}{l}\text { Control } \\
(n=10)\end{array}$ & $\begin{array}{l}\text { Induced } \\
(n=14)\end{array}$ & $\begin{array}{l}\text { Control + CF } \\
(n=5)\end{array}$ & $\begin{array}{l}\text { Induced + CF } \\
(n=9)\end{array}$ \\
\hline \multicolumn{5}{|c|}{ Dorsolateral prostate } \\
\hline \multicolumn{5}{|c|}{ Dysplasia } \\
\hline Absent & $6(60.0 \%)$ & $2(14.3 \%)$ & $0(0 \%)$ & $1(11.1 \%)$ \\
\hline Present & $4(40.0 \%)^{a, b}$ & $12(85.7 \%)$ & $5(100.0 \%)$ & $8(88.9 \%)$ \\
\hline \multicolumn{5}{|l|}{ PIN } \\
\hline Absent & $9(90.0 \%)$ & $5(35.7 \%)$ & $2(40 \%)$ & $3(33.3 \%)$ \\
\hline Present & $1(10.0 \%)^{a, b}$ & $9(64.3 \%)$ & $3(60.0 \%)$ & $6(66.7 \%)$ \\
\hline \multicolumn{5}{|c|}{ Microinvasive carcinoma } \\
\hline Absent & $10(100.0 \%)$ & $5(35.7 \%)$ & $4(80.0 \%)$ & $2(22.2 \%)$ \\
\hline Present & $0(0.0 \%)^{a}$ & $9(64.3 \%)$ & $1(20.0 \%)$ & $7(77.8 \%)$ \\
\hline \multicolumn{5}{|c|}{ Ventral prostate } \\
\hline \multicolumn{5}{|c|}{ Dysplasia } \\
\hline Absent & $10(100.0 \%)$ & $14(100.0 \%)$ & $5(100.0 \%)$ & $7(77.8 \%)$ \\
\hline Present & $0(0.0 \%)$ & $0(0.0 \%)$ & $0(0.0 \%)$ & $2(22.2 \%)$ \\
\hline \multicolumn{5}{|l|}{ PIN } \\
\hline Absent & $10(100.0 \%)$ & $14(100.0 \%)$ & $5(100.0 \%)$ & $8(88.9 \%)$ \\
\hline Present & $0(0.0 \%)$ & $0(0.0 \%)$ & $0(0.0 \%)$ & $1(11.1 \%)$ \\
\hline \multicolumn{5}{|c|}{ Microinvasive carcinoma } \\
\hline Absent & $10(100.0 \%)$ & $10(100.0 \%)$ & $10(100.0 \%)$ & $10(100.0 \%)$ \\
\hline Present & $0(0.0 \%)$ & $0(0.0 \%)$ & $0(0.0 \%)$ & $0(0.0 \%)$ \\
\hline \multicolumn{5}{|c|}{ Anterior prostate } \\
\hline \multicolumn{5}{|c|}{ Dysplasia } \\
\hline Absent & $10(100.0 \%)$ & $14(100 \%)$ & $5(100.0 \%)$ & $6(66.7 \%)$ \\
\hline Present & $0(0.0 \%)$ & $0(0.0 \%)$ & $0(0.0 \%)$ & $3(33.3 \%)$ \\
\hline \multicolumn{5}{|l|}{ PIN } \\
\hline Absent & $10(100.0 \%)$ & $14(100 \%)$ & $5(100.0 \%)$ & $7(77.8 \%)$ \\
\hline Present & $0(0.0 \%)$ & $0(0.0 \%)$ & $0(0.0 \%)$ & $2(22.2 \%)$ \\
\hline \multicolumn{5}{|c|}{ Microinvasive carcinoma } \\
\hline Absent & $10(100.0 \%)$ & $14(100 \%)$ & $5(100.0)$ & $7(77.8 \%)$ \\
\hline Present & $0(0.0 \%)$ & $0(0.0 \%)$ & $0(0.0 \%)$ & $2(22.2 \%)$ \\
\hline
\end{tabular}

${ }^{a} p<0.05$ versus the induced group. ${ }^{b} p<0.05$ versus the control group + CF; PIN - intraepithelial neoplasia.

Table 7 Number of animals (\%) with dysplasia, PIN, and microinvasive carcinoma in all prostate lobes (mean \pm S.E.)

\begin{tabular}{llrll}
\hline & $\begin{array}{l}\text { Control } \\
(n=10)\end{array}$ & $\begin{array}{l}\text { Induced } \\
(n=14)\end{array}$ & $\begin{array}{l}\text { Control + CF } \\
(n=5)\end{array}$ & $\begin{array}{l}\text { Induced + CF } \\
(n=9)\end{array}$ \\
\hline $\begin{array}{l}\text { Dysplasia } \\
\text { Absent }\end{array}$ & $6(60 \%)$ & $2(14.3 \%)$ & $0(0.0 \%)$ & $0(0.0 \%)$ \\
$\begin{array}{l}\text { Present } \\
\text { PIN }\end{array}$ & $4(40 \%)^{a, b}$ & $12(85.7 \%)$ & $5(100.0 \%)$ & $9(100.0 \%)$ \\
Absent & $9(90.0 \%)$ & $6(42.9 \%)$ & $2(40.0 \%)$ & $2(22.2 \%)$ \\
$\begin{array}{l}\text { Present } \\
\text { Microinvasive carcinoma }\end{array}$ & $1(10.0 \%)^{a}$ & $8(57.1 \%)$ & $3(60.0 \%)$ & $7(77.8 \%)$ \\
Absent & $\mathbf{1 0 ( 1 0 0 . 0 \% )}$ & $5(35.7 \%)$ & $4(80.0 \%)$ & $1(11.1 \%)$ \\
Present & $\mathbf{0 ( 0 . 0 \% ) ^ { a }}$ & $9(64.3 \%)$ & $1(20.0 \%)^{c}$ & $8(88.9 \%)$
\end{tabular}

${ }^{a} p<0.05$ versus induced group. ${ }^{b} p<0.05$ versus control + CF group. ${ }^{c} p$ $<0.05$ versus induced + CF group.

(Table 9). All animals from the induced + CF group developed small multifocal non-purulent interstitial nephritis foci, whereas focal nephritis was just observed in $42.9 \%$ (6/14) of animals from the induced group. No animals exposed to the CF extract developed chronic multifocal lesions, but these lesions were observed in $21.4 \%(3 / 14)$ of the non-treated animals (Table 9).

\subsection{Oxidative stress evaluation}

Nonspecific lipid peroxidation levels were evaluated by the formed TBARS products in both lipid fractions - total and mitochondrial (Fig. 3). The induced group and the groups exposed to the CF extract (control and induced) showed similar levels of formed TBARS products in the total and mitochondrial fraction. Induced animals showed a decrease of $28 \%$ and $24 \%$ of lipid peroxidation levels in total and mitochondrial fractions, respectively, when compared to control animals. However, this reduction did not reach statistical significance $(p>0.05)$. The administration of the CF extract to the control group led to a statistically significant decrease of the formed TBARS products by $68 \%$ and $57 \%$ of the total and mitochondrial fraction, respectively $(p=0.004)$. However, the administration of the $\mathrm{CF}$ extract in the induced animals caused a $25 \%$ increase in lipid peroxidation in both lipid fractions, when compared with the control + CF group $(p>0.05)$. Prostate cancer induction and administration of the CF extract to both control and induced rats did not promote any statistically significant alteration in GSH/GSSG $(p>0.05)$ (Fig. 4). The activity of antioxidant enzymes showed a different response to cancer induction and CF extract treatment. SOD and GR activity did not show statistically significative alterations in any experimental group. An increase of $32 \%$ and $17 \%$ was observed in CAT and GST activity, respectively $(p<0.007)$. The administration of CF to control animals did not promote any alteration in the activity of antioxidant enzymes when compared to the control group. In induced animals, the administration of CF decreased the activity of CAT and GST by $36 \%$ and $20 \%$, respectively $(p<0.0007)$. The administration of the CF extract to the induced group led to the activities of CAT and GST being close to the values observed in the control group. Thus, CF extract administration seems to induce a normalization of the enzymatic antioxidant system (Fig. 5).

\section{Discussion}

Rats are commonly used as models in experimental PCa research. ${ }^{3,26}$ Although rat and human prostates have anatomical differences, the mechanisms underlying prostate tumorigenesis are similar. ${ }^{4}$ While the human prostate is a compact and a lobular structure, the rat prostate is composed of four lobes - the ventral, dorsal, lateral and anterior lobe (or coagulating gland) - with different histological characteristics. ${ }^{27,28}$ The dorsal and lateral lobes are commonly referred to as the dorsolateral lobe due to the difficulty of anatomical division and similar histological features. ${ }^{29}$ These lobes are homologous to the peripheral zone of the human prostate, ${ }^{30}$ where most carcinomas arise. ${ }^{31}$ The induction protocol used in the present work was based on the works previously published by Bosland, ${ }^{26,32}$ where a multistep protocol was employed animals were administered with an antiandrogen, testosterone propionate, a specific carcinogen and chronically exposed to testosterone using subcutaneous implants. ${ }^{26,32,33}$ Prostate 

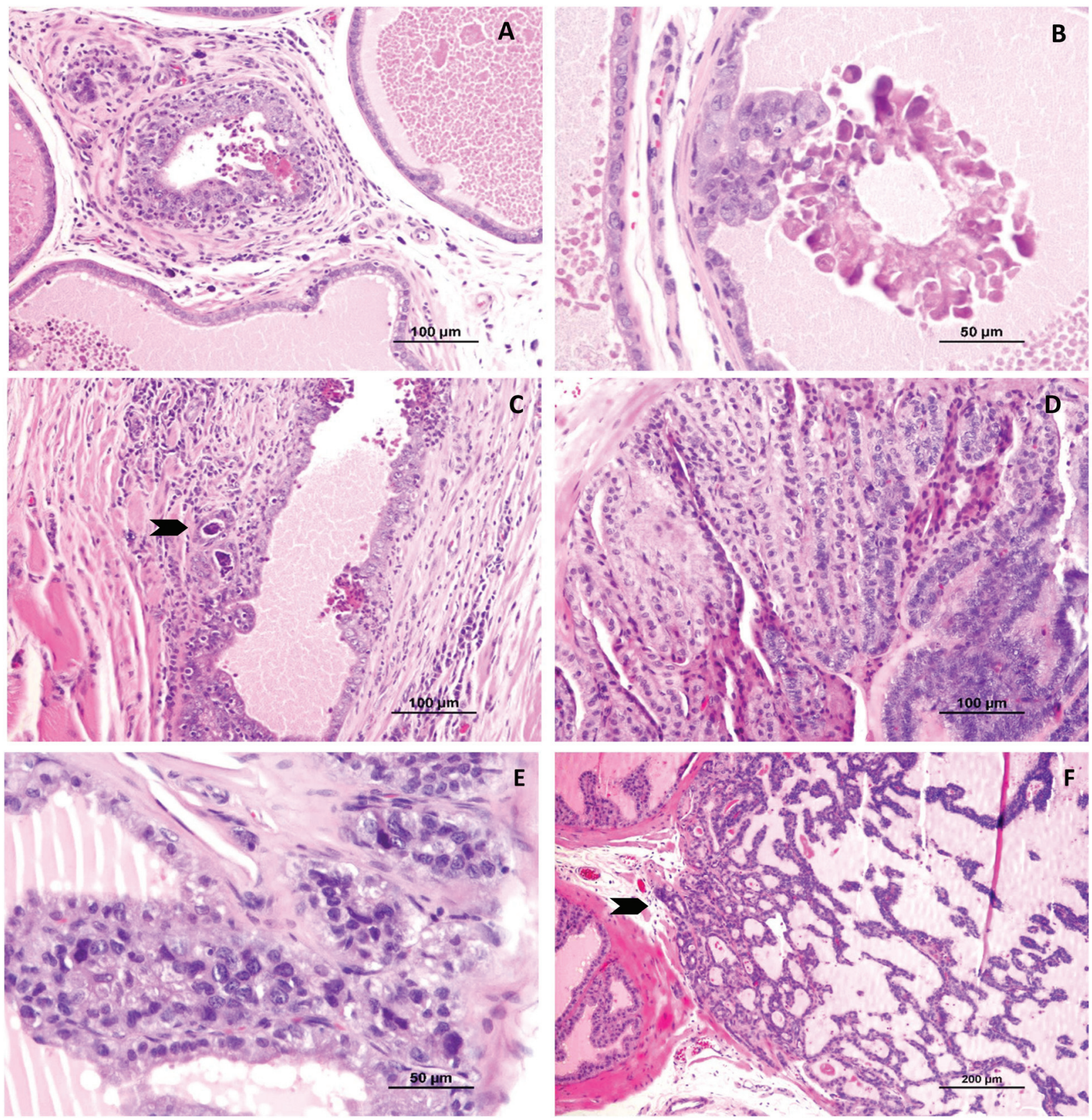

Fig. 2 Histopathological lesions observed in the dorsolateral prostate, DLP, (A-C) and in the anterior prostate, $A P,(D-F)$ via hematoxylin and eosin staining: (A) dysplasia in the DLP, (B) intraepithelial neoplasia in situ (PIN) in the DLP, (C) microinvasive carcinoma in the DLP (the arrow shows the invasion front of the tumor, with carcinoma cells forming small tubules and nests), (D) hyperplasia in the AP, (E) PIN in the AP, and (F) microinvasive carcinoma in the AP (the arrow shows invasive tumor cell nests).

Table 8 Number (\%) of animals with chronic active inflammation in the dorsolateral prostate lobe

\begin{tabular}{lllll}
\hline $\begin{array}{l}\text { Inflammation } \\
\text { extension }\end{array}$ & $\begin{array}{l}\text { Control } \\
(n=10)\end{array}$ & $\begin{array}{l}\text { Induced } \\
(n=14)\end{array}$ & $\begin{array}{l}\text { Control + CF } \\
(n=5)\end{array}$ & $\begin{array}{l}\text { Induced + CF } \\
(n=9)\end{array}$ \\
\hline$<10 \%$ & $2(20.0 \%)$ & $0(0.0 \%)$ & $0(0.0 \%)$ & $0(0.0 \%)$ \\
$10-50 \%$ & $8(80.0 \%)$ & $7(50.0 \%)^{a}$ & $5(100.0 \%)$ & $9(100.0 \%)$ \\
$>50 \%$ & $0(0.0 \%)^{b}$ & $7(50.0 \%)^{a}$ & $0(0.0 \%)$ & $0(0.0 \%)$
\end{tabular}

${ }^{a} p<0.05$ versus the induced $+\mathrm{CF}$ group. ${ }^{b} p<0.05$ versus induced group. tumours are mainly induced in the dorsolateral and anterior prostate lobes. ${ }^{26,32,33}$

Natural compounds are widely used against several diseases, including cancer. ${ }^{6,34,35}$ The chestnut tree, a typical Mediterranean tree, has a variety of applications. ${ }^{15}$ The flowers have been used for medical purposes due to their antioxidant properties and antimicrobial and antitumoral effects. ${ }^{11,18}$

In the present work, the effect of the CF extract was evaluated in a rat model of chemically and hormonally induced PCa. The mean final body weight of animals exposed to CF 
Table 9 Number of animals (\%) with liver and kidney histological lesions in all experimental groups (mean $\pm \mathrm{SE}$ )

\begin{tabular}{|c|c|c|c|c|}
\hline & $\begin{array}{l}\text { Control } \\
(n=10)\end{array}$ & $\begin{array}{l}\text { Induced } \\
(n=14)\end{array}$ & $\begin{array}{l}\text { Control + } \\
\text { CF }(n=5)\end{array}$ & $\begin{array}{l}\text { Induced + } \\
\text { CF }(n=9)\end{array}$ \\
\hline \multicolumn{5}{|l|}{ Liver } \\
\hline \multicolumn{5}{|l|}{ Cell changes } \\
\hline Absent & $8(80.0 \%)^{a}$ & $6(42.9 \%)$ & $3(60.0 \%)$ & $0(0.0 \%)$ \\
\hline $\begin{array}{l}\text { Focal vacuolar } \\
\text { change }\end{array}$ & $2(20.0 \%)$ & $5(35.7 \%)^{b}$ & $0(0.0 \%)$ & $0(0.0 \%)$ \\
\hline $\begin{array}{l}\text { Slight hydropic } \\
\text { change }\end{array}$ & $0(0.0 \%)$ & $3(21.4 \%)$ & $2(40.0 \%)$ & $6(66.7 \%)$ \\
\hline $\begin{array}{l}\text { Moderate } \\
\text { hydropic } \\
\text { change }\end{array}$ & $0(0.0 \%)$ & $0(0.0 \%)$ & $0(0.0 \%)$ & $3(33.3 \%)$ \\
\hline \multicolumn{5}{|c|}{ Inflammatory infiltrate } \\
\hline Absent & $3(30.0 \%)^{c}$ & $3(21.4 \%)$ & $5(100 \%)$ & $4(44.4 \%)$ \\
\hline Focal & $7(70.0 \%)^{c}$ & $11(78.6 \%)$ & $0(0.0 \%)$ & $5(55.6 \%)$ \\
\hline Extensive & $0(0.0 \%)$ & $0(0.0 \%)$ & $0(0.0 \%)$ & $0(0.0 \%)$ \\
\hline \multicolumn{5}{|l|}{ Necrosis } \\
\hline Absent & $10(100.0 \%)$ & $12(85.7 \%)$ & $5(100.0 \%)$ & $8(88.9 \%)$ \\
\hline Focal & $0(0.0 \%)$ & $2(14.28 \%)$ & $0(0.0 \%)$ & $1(11.1 \%)$ \\
\hline \multicolumn{5}{|c|}{ Kidney } \\
\hline \multicolumn{5}{|c|}{ Non-purulent interstitial nephritis } \\
\hline Absent & $3(30.0 \%)$ & $4(28.6 \%)$ & $1(20.0 \%)$ & $0(0.0 \%)$ \\
\hline Focal & $5(50.0 \%)$ & $4(28.6 \%)$ & $4(80.0 \%)^{b}$ & $0(0.0 \%)$ \\
\hline Multifocal $\ldots$ & $2(20.0 \%)$ & $6(42.9 \%)$ & $0(0.0 \%)^{b}$ & $9(100.0 \%)$ \\
\hline \multicolumn{5}{|l|}{ Chronic nephritis } \\
\hline Absent & $8(80.0 \%)^{a}$ & $5(35.7 \%)$ & $1(20.0 \%)$ & $5(55.6 \%)$ \\
\hline Focal & $1(10.0 \%)^{c}$ & $6(42.9 \%)$ & $4(80.0 \%)$ & $4(44.4 \%)$ \\
\hline Multifocal & $1(10.0 \%)$ & $3(21.4 \%)^{b}$ & $0(0.0 \%)$ & $0(0.0 \%)$ \\
\hline \multicolumn{5}{|l|}{ Proteinuria } \\
\hline Absent & $5(50.0 \%)$ & $5(35.7 \%)$ & $4(89.0 \%)^{b}$ & $0(0.0 \%)$ \\
\hline Discrete & $5(50.0 \%)$ & $9(64.3 \%)$ & $1(20.0 \%)^{b}$ & $9(100.0 \%)$ \\
\hline Intense & $0(0.0 \%)$ & $0(0.0 \%)$ & $0(0.0 \%)$ & $0(0.0 \%)$ \\
\hline \multicolumn{5}{|c|}{ Cytomegalocytosis } \\
\hline No & $10(100.0 \%)$ & $14(100.0 \%)$ & $5(100.0 \%)$ & $7(77.8 \%)$ \\
\hline Yes & $0(0.0 \%)$ & $0(0.0 \%)$ & $0(0.0 \%)$ & $2(22.2 \%)$ \\
\hline
\end{tabular}

${ }^{a} p<0.05$ versus the induced group. ${ }^{b} p<0.05$ versus the induced $+\mathrm{CF}$ group. ${ }^{c} p<0.05$ versus control + CF group.

flower extract was not different from the respective control groups. The animals' body weight increased throughout the study in all experimental groups. The animals from control

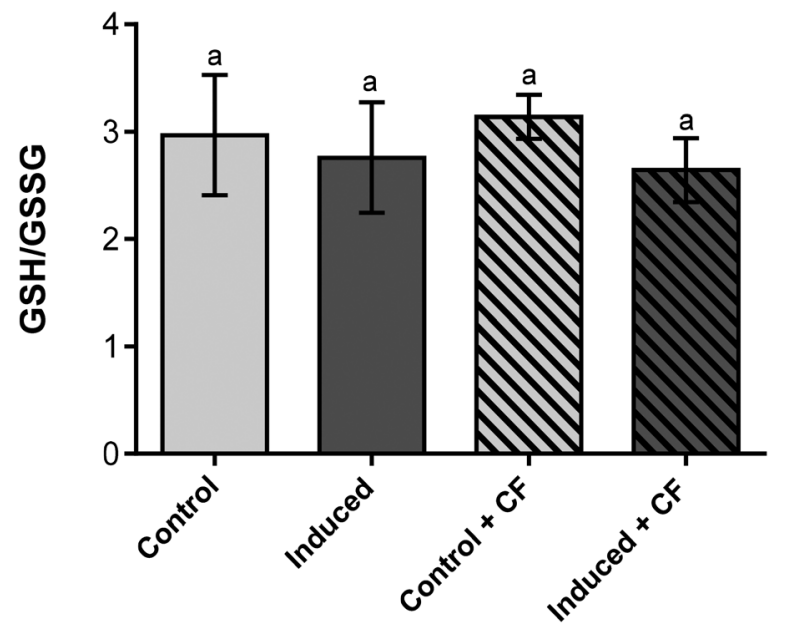

Fig. 4 Evaluation of the hepatic GSH/GSSG ratio. Results were obtained from the four experimental groups: control, induced, control $+\mathrm{CF}$, and induced + CF groups. Columns with different letters were statistically different $(p<0.05)$. Data are presented as mean \pm S.D. $(n=7)$ from two replicates.

and induced groups exposed to the CF extract showed a lower water intake when compared to the unexposed groups, which may be related to the water taste due to the presence of $\mathrm{CF}$ extract. One of the requisite of a rat PCa model is the development of adenocarcinomas histologically similar to those developed by men in the dorsal and lateral prostate lobes, which are human homologues. ${ }^{26}$ In this study, preneoplastic and neoplastic prostate lesions were found mainly in the dorsolateral lobe. These data are in accordance with previous studies employing a similar experimental protocol, which reported an incidence of carcinomas in the dorsolateral prostate of approximately $60-80 \%$, within $50-60$ weeks after MNU administration. ${ }^{36-42}$ In our study, CF was not associated with an increased frequency of pre-neoplastic and neoplastic lesions in the dorsolateral prostate in the induced groups but
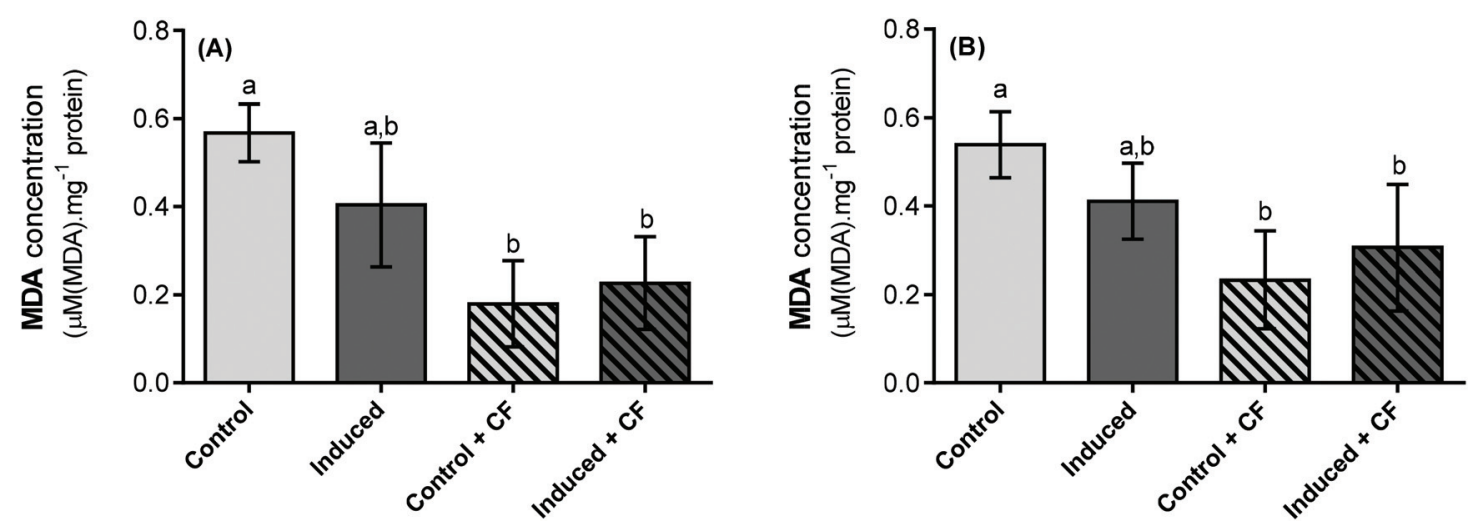

Fig. 3 Evaluation of hepatic lipid peroxidation: (A) MDA concentrations in the total lipidic fraction isolated from livers and (B) the MDA concentrations in the mitochondrial lipidic fraction isolated from livers. Results were obtained from the four experimental groups: control, induced, control $+\mathrm{CF}$, and induced + CF groups. Columns with different letters were statistically different $(p<0.05)$. Data are presented as mean \pm S.D. $(n=7)$ from two replicates. 

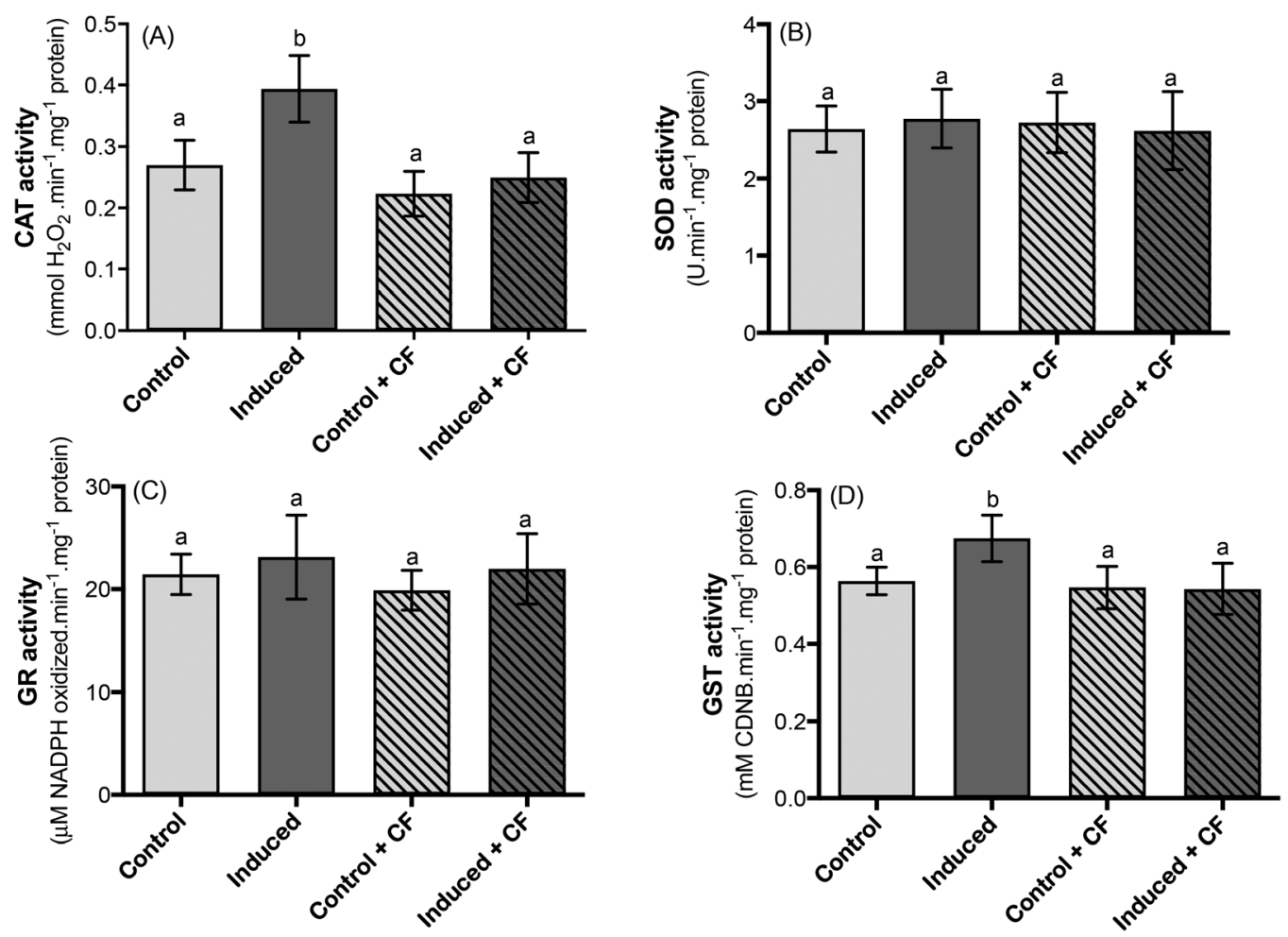

Fig. 5 Evaluation of hepatic antioxidant enzymes: (A) catalase activity; (B) superoxide dismutase activity; (C) glutathione reductase activity; and (D) glutathione-S-transferase activity. Results were obtained from the four experimental groups: control, induced, control $+\mathrm{CF}$, and induced $+\mathrm{CF}$ groups. Columns with different letters were statistically different $(p<0.05)$. Data are presented as mean \pm S.D. $(n=7)$ from two replicates.

was associated with a slight increase of the frequency of lesions on the control + CF compared to the control group. Considering that these animals were not exposed to hormonal treatment or carcinogen administration, and accounting the animals' age at sacrifice (61 weeks of age), they may be considered old; previous studies showed that aged Wistar rats are susceptible to spontaneous lesions that mimic human prostate alterations. ${ }^{43}$ Correlating the laboratory rat and human ages, ${ }^{44}$ we estimate that our rats correspond to a man over 40 years old. At this age, the human prostate is more likely to develop prostate disorders, such as benign prostate hyperplasia. ${ }^{45}$ It also is important to highlight that functional hyperplasia is commonly associated with prostate aging and may occur in all animal species. Regarding ventral and anterior prostate $\mathrm{CF}$ exposure, in induced animals there was a slight increase in lesions frequency, but there were no significant differences.

All groups showed inflammation in the dorsolateral prostate, which is in accordance with previous published studies. ${ }^{46}$ In the prostate, the CF extract appears to decrease the severity of inflammation, as exposed CF animals showed fewer inflammation areas.

The highest mean relative liver weight was observed in induced animals treated with the CF extract, but these differences were not supported by biochemical parameters. For example, the circulating levels of ALT, a marker of liver damage ${ }^{47,48}$ was not different among the groups. Macroscopically, most livers from the CF exposed animals had increased in size and were paler than normal. These gross changes in liver colour, size and weight can be associated with hydropic changes observed microscopically, although it was always focal, slight to mild. In fact, just three induced animals + CF developed panlobular and mild hydropic changes, and no severe degenerative, necrotizing or inflammatory lesions were observed in this study. The hydropic changes observed in liver are usually associated with $\mathrm{Na}^{+} / \mathrm{K}^{+}$pump disfunction rather than with lipid cytoplasmic overload.

Circulating androgens play a role in prostate growth, which will be strongly influenced by liver function, as most circulating androgen dihydrotestosterone originates in the liver. For this reason, liver disease has been suggested to influence the incidence of PCa. Nevertheless, the effect of liver function on prostate lesions and PCa outcomes has not yet been elucidated. ${ }^{49,50}$

Our results showed that PCa induction had an impact on the hepatic antioxidant system, stimulating some of the antioxidant enzymes analyzed. Systemic and prostate dysregulation of redox balance has already been documented in $\mathrm{PCa}$, although the results are not similar. ${ }^{51-53}$ Nevertheless, in this model, we may consider the toxic effect of chronic testosterone exposure on liver tissue, as testosterone was released through implants until the animals' euthanasia. Therefore, the direct impact on biomarkers cannot be excluded from the two exposed groups. The CF extract induced a reduction in lipid peroxidation in all groups (control and induced), both in 
plasma and in the mitochondrial membranes, although not a statistically significant difference. However, it is clear that under the conditions tested, CF has a beneficial and protective effect at the lipid membrane level, which probably results from the action of some compounds that, due to their physical properties, tend to accumulate on the lipid membranes and exert a protective effect. Effects of testosterone on reactive oxygen species (ROS) generation and oxidant status are a controversial subject. Depending on the experimental conditions, we may observe an increase or a decrease in lipid peroxidation measured by MDA production. ${ }^{54-58}$ The results regarding antioxidant activities (SOD) are also variable, depending not only on the experimental model, but also on the testosterone concentration administered. ${ }^{59,60}$ Regarding the activation of GST (phase II enzyme), the effect observed in the liver has already been described by the action of flutamide and testosterone. ${ }^{61,62}$ Although few reports have addressed the antioxidant potential of $\mathrm{CF},{ }^{18}$ a small number of studies have focused on the antioxidant response induced by the consumption of CF extracts. The presence of phenolic compounds and some organic acids in the CF extract justify, among other beneficial activities, the observed antioxidant activity, as they are capable of free radical scavenging. ${ }^{15}$ However, most studies used an in vitro approach resulting in a lack of knowledge regarding the antioxidant response induced by $\mathrm{CF}$ consumption. ${ }^{63}$ The enteral administration of the CF extract leads to a systemic effect. Given the role of the liver in the metabolism of substances that enter the gastrointestinal tract, it is expected that the CF extract leads to changes in hepatic function. In our results, the administration of $\mathrm{CF}$ in $\mathrm{PCa}$-induced animals significantly changed CAT, which came close to the control group, suggesting a beneficial effect on oxidative stress induced cancer. The decreased activity of antioxidant enzymes, as well as lipid peroxidation levels observed with administration of the CF extract may be interpreted as a response to reduced ROS levels.

\section{Conclusions}

The most interesting finding from this study was the reduction of inflammation on the dorsolateral prostate lobe. The CF extract did not cause significant hepatic and renal toxicity, as observed microscopically and via biochemical tests. Regarding the effects of CFs on dorsolateral prostate tumorigenesis, no significant differences were achieved between the induced and induced + CF groups. Apparently, the CF extract has no significant effect on MNU-initiated dorsal prostate cells. As inflammation may act as a promotor (inflammation mediators, as ROS, can also be initiators), the anti-inflammatory effects may also have a protective influence against prostate tumorigenesis.

The results from the different experimental groups corroborate the existence of physiological alterations in the livers of animals with PCa, and they also showed that the use of CFs in this group (PCa) induced changes in some enzymes of the antioxidant system (CAT and GST). Considering the animal model used, with animals subjected to prolonged testosterone exposure, it is plausible that the results relating to oxidative stress mainly reflect the effects of testosterone. New studies are warranted to elucidate the real role of antioxidant enzymes, oxidative stress, and the action of testosterone, not only in the prostate but also in other organs. Also, new studies on CFs using different doses should be performed to clarify if CFs are in fact toxic in rat and/or human livers.

\section{Author contributions}

E. Nascimento-Gonçalves conducted experiments with live animals and wrote the manuscript; F. Seixas performed the histopathological evaluation and wrote the manuscript; M. Fardilha performed the biochemical analysis and wrote the manuscript; R. Ferreira performed the experimental design, participated in animals sacrifice and wrote the manuscript; M. J. Neuparth performed the biochemical analysis and wrote the manuscript; A. I. Faustino-Rocha conducted the experiments with live animals and wrote the manuscript; B. Colaço and C. Venâncio participated in the animal sacrifice and sample processing and wrote the manuscript; L. Barros and I. C. F. R. Ferreira performed Castanea sativa Mill. flowers extract preparation and characterization and wrote the manuscript; M. Silva, M. M. Oliveira and F. Peixoto performed oxidative stress studies and wrote the manuscript; E. Rosa was responsible for funding acquisition, performed the experimental design and wrote the manuscript; and P. A. Oliveira performed the experimental design, supervised the animal experiments, participated in the animal sacrifice and wrote the manuscript.

\section{Conflicts of interest}

All authors declare no actual, potential, or perceived conflicts of interest that would prejudice the impartiality of the article.

\section{Acknowledgements}

This work was supported by European Investment Funds by FEDER/COMPETE/POCI - Operational Competitiveness and Internationalization and National Funds by FCT - Portuguese Foundation for Science and Technology, under the projects UIDB/04033/2020 (CITAB), UIDB/00690/2020 (CIMO), UIDB/ 50006/2020 (LAQV), UIDB/CVT/00772/2020 (CECAV), and UIDP/ 00616/2020 (CQ-VR), the project RUNawayPCa (POCI-01-0145FEDER-016728 and PTDC/DTP-DES/6077/2014), and PhD fellowship SFRH/BD/136747/2018. L. Barros also acknowledges national funding by FCT, P.I., through the institutional scientific employment program-contract for her contract. The Interreg Program received financial support from the Project IBERPHENOL, Project Number 0377_IBERPHENOL_6_E, cofinanced by the European Regional Development Fund (ERDF) through POCTEP 2014-2020. 


\section{References}

1 Globocan, Estimated Incidence, Mortality and Prevalence Worldwide in 2018, International Agency for Research on Cancer (Word Health Organization), 2018, http://gco.iarc.fr/.

2 M. C. Bosland, N. Ozten, J. Eskra, et al., A Perspective on Prostate Carcinogenesis and Chemoprevention, Curr. Pharmacol. Rep., 2015, 1, 258-265.

3 T. Shirai, S. Takahashi, L. Cui, et al., Experimental prostate carcinogenesis-rodent models, Mutat. Res., 2000, 462, 219-226.

4 E. Nascimento-Gonçalves, A. I. Faustino-Rocha, F. Seixas, et al., Modelling human prostate cancer: Rat models, Life Sci., 2018, 203, 210-224.

5 Y.-H. Song, H. Sun, A.-H. Zhang, et al., Plant-derived natural products as leads to anti-cancer drugs, J. Med. Plant Herb. Ther. Res., 2014, 2, 6-15.

6 A. da Rocha, R. Lopes and G. Schwartsmann, Natural products in anticancer therapy, Curr. Opin. Pharmacol., 2001, 1, 364-369.

7 M. Carocho and I. C. F. R. Ferreira, The Role of Phenolic Compounds in the Fight against Cancer - A Review, Anticancer Agents Med. Chem., 2013, 13, 1236-1258.

8 J. Wang, I. E. Eltoum and C. A. Lamartiniere, Dietary genistein suppresses chemically induced prostate cancer in Lobund-Wistar rats, Cancer Lett., 2002, 186, 11-18.

9 J.-F. Bisson, M.-A. Guardia-Llorens, S. Hidalgo, et al., Protective effect of Acticoa powder, a cocoa polyphenolic extract, on prostate carcinogenesis in Wistar-Unilever rats, Eur. J. Cancer Prev., 2008, 17, 54-61.

10 D. Guru Kumar, V. Parvathi, P. Meenakshi, et al., Anticancer activity of the ethanolic extract of Crateva nurvala bark against testosterone and MNU-induced prostate cancer in rats, Chin. J. Nat. Med., 2012, 10, 334-338.

11 M. Carocho, J. C. M. Barreira, A. Bento, et al., Chestnut flowers as functionalizing agents to enhance the antioxidant properties of highly appreciated tradional pastry, Food Funct., 2014, 5, 2989-2995.

12 J. C. M. Barreira, S. Casal, I. C. F. R. Ferreira, et al., Chemical characterization of chestnut cultivars from three consecutive years: Chemometrics and contribution for authentication, Food Chem. Toxicol., 2012, 50, 2311-2317.

13 P. Rodrigues, T. Ferreira, E. Nascimento-Gonçalves, et al., Dietary Supplementation with Chestnut (Castanea sativa) Reduces Abdominal Adiposity in FVB/n Mice: A Preliminary Study, Biomedicines, 2020, 8, 75.

14 E. Rosa, M. Morais and I. Oliveira, et al., Uses and health benefits of chestnuts, in Achieving sustainable cultivation of tree nuts, Burleigh Dodds Science Publishing, Cambridge, UK, 2019, pp. 69-108.

15 M. Carocho, L. Barros, A. Bento, et al., Castanea sativa Mill. Flowers amongst the Most Powerful Antioxidant Matrices: A Phytochemical Approach in Decoctions and Infusions, BioMed Res. Int., 2014, 2014, 232956.

16 T. K. Lim, Edible Medicinal and Non-Medicinal Plants, Springer, 2012.
17 J. Manuel, C. Matos, C. Moutinho, et al., Ethnopharmacological notes about ancient uses of medicinal plants in Trás-os-Montes (northern of Portugal), J. Ethnopharmacol., 2009, 124, 270-283.

18 M. Carocho, R. C. Calhelha, M. R. P. Queiroz, et al., Infusions and decoctions of Castanea sativa flowers as effective antitumor and antimicrobial matrices, Ind. Crops Prod., 2014, 62, 42-46.

19 B. Medeiros-Fonseca, V. F. Mestre, B. Colaço, et al., Laurus nobilis (laurel) aqueous leaf extract's toxicological and antitumor activities in HPV16-transgenic mice, Food Funct., 2018, 9, 4419-4428.

20 M. C. Bosland, Proliferative Lesions of the Prostate and Other Accessory Sex Glands in Male Rats, Society of Toxicologic Pathologists, 1998.

21 A. Ottolenghi, Interaction of ascorbic acid and mitochondrial lipides, Arch. Biochem. Biophys., 1959, 79, 355-363.

22 P. J. Hissin and R. Hilf, A fluorometric method for determination of oxidized and reduced glutathione in tissues, Anal. Biochem., 1976, 74, 214-226.

23 L. A. Del Río, M. G. Ortega, A. L. López, et al., A more sensitive modification of the catalase assay with the Clark oxygen electrode. Application to the kinetic study of the pea leaf enzyme, Anal. Biochem., 1977, 80, 409-415.

24 M. Payá, B. Halliwell and J. R. Hoult, Interactions of a series of coumarins with reactive oxygen species. Scavenging of superoxide, hypochlorous acid and hydroxyl radicals, Biochem. Pharmacol., 1992, 44, 205-214.

25 I. Carlberg and B. Mannervik, Glutathione reductase, Methods Enzymol., 1985, 113, 484-490.

26 M. C. Bosland, Animal models for the study of prostate carcinogenesis, J. Cell. Biochem., 1992, 50, 89-98.

27 C. Lee and J. M. Holland, Anatomy, Histology, and Ultrastructure (Correlation with Function), Prostate, Rat, in Genital System, ed. T. C. Jones, U. Mohr and R. D. Hunt, Springer Berlin Heidelberg, Berlin, Heidelberg, 1987, pp. 239-251.

28 C. J. Jesik, J. M. Holland and C. Lee, An anatomic and histologic study of the rat prostate, Prostate, 1982, 3, 81-97.

29 M. Ginja, M. J. Pires, J. M. Gonzalo-Orden, et al., Anatomy and Imaging of Rat Prostate: Practical Monitoring in Experimental Cancer-Induced Protocols, Diagnostics, 2019, 9, 68.

30 M. C. Bosland, Use of Animal Models in Defining Efficacy of Chemoprevention Agents against Prostate Cancer, Eur. Urol., 1999, 35, 459-463.

31 A. Bhavsar and S. Verma, Anatomic Imaging of the Prostate, BioMed Res. Int., 2014, 2014, 1-9.

32 M. C. Bosland, Chemical and hormonal induction of prostate cancer in animal models, Urol. Oncol.: Semin. Orig. Invest., 1996, 2, 103-110.

33 M. C. Bosland, Testosterone Treatment Is a Potent Tumor Promoter for the Rat Prostate, Endocrinology, 2014, 155, 4629-4633.

34 M. M. Cowan, Plant products as antimicrobial agents, Clin. Microbiol. Rev., 1999, 12, 564-582. 
35 T. Ferreira, E. Nascimento-Gonçalves, R. M. Gil Da Costa, et al., Therapeutic and toxicological effects of natural compounds: Data from HPV16-transgenic and ICR mice (Review), World Acad. Sci. J., 2020, 2, 1-1.

36 Z. Liao, T. W.-M. Boileau, J. W. Erdman Jr., et al., Interrelationships among angiogenesis, proliferation, and apoptosis in the tumor microenvironment during $\mathrm{N}$-methyl-N-nitrosourea androgen-induced prostate carcinogenesis in rats, Carcinogenesis, 2002, 23, 1701-1711.

37 M. C. Bosland, M. K. Prinsen and R. Kroes, Adenocarcinomas of the prostate induced by N-Nitroso$\mathrm{N}$-Methylurea in rats preteated with cyproterone acetate and testosterone, Cancer Lett., 1983, 18, 69-78.

38 D. L. McCormick, W. D. Johnson, T. M. Haryu, et al., Null Effect of Dietary Restriction on Prostate Carcinogenesis in the Wistar-Unilever Rat, Nutr. Cancer, 2007, 57, 194-200.

39 D. L. McCormick, W. D. Johnson, M. C. Bosland, et al., Chemoprevention of Rat Prostate Carcinogenesis by Soy Isoflavones and by Bowman-Birk Inhibitor, Nutr. Cancer, 2007, 57, 184-193.

40 N. K. Narayanan, D. Nargi, L. Horton, et al., Inflammatory processes of prostate tissue microenvironment drive rat prostate carcinogenesis: Preventive effects of celecoxib, Prostate, 2009, 69, 133-141.

41 D. L. Mccormick, K. V. N. Rao, L. Dooley, et al., Influence of N-Methyl-N-Nitrosourea, Testosterone, and N-(4Hydroxyphenyl)-all- trans-retinamide on Prostate Cancer Induction in Wistar-Unilever Rats, Cancer Res., 1998, 58, 3282-3288.

42 H. Chiu, M. Chen, W. Fang, et al., Preventive Effects of Monascus on Androgen-Related Diseases: Androgenetic Alopecia, Benign Prostatic Hyperplasia, and Prostate Cancer, J. Agric. Food Chem., 2013, 61, 4379-4386.

43 G. H. Campolina-Silva, H. Werneck-Gomes, B. T. Maria, et al., Targeting Wistar rat as a model for studying benign, premalignant and malignant lesions of the prostate, Life Sci., 2020, 242, 117149.

44 P. Sengupta, The Laboratory Rat: Relating Its Age With Human's, Int. J. Prev. Med., 2013, 4, 624-630.

45 Prostate Cancer Risk Factors, https://www.cancer.org/ cancer/prostate-cancer/causes-risks-prevention/risk-factors. html (accessed 15 June 2020).

46 M. C. Bosland, M. K. Prinsen, T. J. Dirksen, et al., Characterization of adenocarcinomas of the dorsolateral prostate induced in Wistar rats by N-methyl-N-nitrosourea, 7,12-dimethylbenz(a)anthracene, and 3,2'-dimethyl-4-aminobiphenyl, following sequential treatment with cyproterone acetate and testosterone propionate, Cancer Res., 1990, 50, 700-709.

47 W. R. Kim, S. L. Flamm, D. A. M. Bisceglie, et al., Serum Activity of Alanine Aminotransferase (ALT) as an Indicator of Health and Disease, Hepatology, 2008, 1363-1370.

48 D. S. El-agamy, Comparative effects of curcumin and resveratrol on aflatoxin B1 -induced liver injury in rats, Arch. Toxicol., 2010, 84, 389-396.
49 S. Melmed, K. Polonsky and P. R. Larsen, et al., Textbook of Endocrinology, Elsevier-Health Sciences Division, Philadelphia, USA, 2015.

50 L. L. Bañez, R. M. Loftis, S. J. Freedland, et al., The influence of hepatic function on prostate cancer outcomes after radical prostatectomy, Prostate Cancer Prostatic Dis., 2010, 13, 173-177.

51 B. Oh, G. Figtree, D. Costa, et al., Oxidative stress in prostate cancer patients: A systematic review of case control studies, Prostate Int., 2016, 4, 71-87.

52 S. A. Ahmed Amar, R. Eryilmaz, H. Demir, et al., Determination of oxidative stress levels and some antioxidant enzyme activities in prostate cancer, Aging Male, 2019, 22, 198-206.

53 N. Kotrikadze, M. Alibegashvili, M. Zibzibadze, et al., Activity and content of antioxidant enzymes in prostate tumors, Exp. Oncol., 2008, 30, 244-247.

54 T. Mostafa, L. Rashed, K. Kotb, et al., Effect of testosterone and frequent low-dose sildenafil/tadalafil on cavernous tissue oxidative stress of aged diabetic rats, Andrologia, 2012, 44, 411-415.

55 C. Skogastierna, M. Hotzen, A. Rane, et al., A supraphysiological dose of testosterone induces nitric oxide production and oxidative stress, Eur. J. Prev. Cardiol., 2014, 21, 10491054.

56 D. P. Marin, A. P. Bolin, R. d. C. dos Santos, et al., Testosterone suppresses oxidative stress in human neutrophils, Cell Biochem. Funct., 2010, 28, 394-402.

57 L. Zhang, S. Wu, Y. Ruan, et al., Testosterone suppresses oxidative stress via androgen receptor-independent pathway in murine cardiomyocytes, Mol. Med. Rep., 2011, 4, 1183-1188.

58 O. Pansarasa, G. D’Antona, M. R. Gualea, et al., 'Oxidative stress': effects of mild endurance training and testosterone treatment on rat gastrocnemius muscle, Eur. J. Appl. Physiol., 2002, 87, 550-555.

59 H. Choobineh, S. Gilani MA, P. Pasalar, et al., The Effects of Testosterone on Oxidative Stress Markers in Mice with Spinal Cord Injuries, Int. J. Fertil. Steril., 2016, 10, 8793.

60 R. B. Azevedo, Z. G. Lacava, C. K. Miyasaka, et al., Regulation of antioxidant enzyme activities in male and female rat macrophages by sex steroids, Braz. J. Med. Biol. Res., 2001, 34, 683-687.

61 M. M. Tawfeeq, H. Hayashi, K. Shimamoto, et al., Mechanistic study on liver tumor promoting effects of flutamide in rats, Arch. Toxicol., 2012, 86, 497-507.

62 Y. Verma and S. V. S. Rana, Influence of testosterone on phase-II enzymes in liver and kidney of benzene-treated rats, Toxicol. Environ. Chem., 2014, 96, 1238-1247.

63 J.-R. Noh, G.-T. Gang, Y.-H. Kim, et al., Antioxidant effects of the chestnut (Castanea crenata) inner shell extract in t-BHP-treated HepG2 cells, and CCl4- and highfat diet-treated mice, Food Chem. Toxicol., 2010, 48, 31773183. 